\title{
LA INSTITUCIÓN FICTICIA. LITERATURA Y FENOMENOLOGÍA EN JACQUES DERRIDA
}

\author{
Iván Trujillo ${ }^{1}$ \\ University of California, Riverside \\ Riverside, California, Estados Unidos \\ itrujillocorrea@gmail.com
}

RESUMEN / ABSTRACT

Exponemos aquí la relación entre el pensamiento de la literatura del filósofo Jacques Derrida y la fenomenología trascendental. Abordamos esta relación a partir de dos recepciones de Derrida en los Estados Unidos procedentes del campo literario. Ambas parecen suponer la toma de distancia de Derrida de la filosofía o, al menos, de la filosofía de Husserl. A partir de un seminario inédito, comenzamos situando el problema de la historicidad de la literatura. Porque este problema es indisociable de un cierto poder de ficción asociado tanto al derecho como a la idea moderna de democracia, mostramos, en segundo lugar, que la idea derridiana de la literatura como "institución ficticia" es elaborada en relación con una experiencia no tética de la tesis ligada a la reducción trascendental husserliana. Finalmente, situamos en el libro Dar la muerte dos momentos en que dicha experiencia equivale a la experiencia pública, ético-política, de un cierto secreto.

Palabras clave: literatura, fenomenología, ficción, institución, espacio público.

1 Dr. en Filosofía, Universidad Paris X / Universidad de Chile. El presente artículo es el resultado de un primer seminario realizado en la Universidad de California - Riverside, en el marco de una beca de postdoctorado en el extranjero (Conicyt, Beca Chile en el Extranjero, Folio 74180106). 


\section{THE FICTIVE INSTITUTION. \\ ON LITERATURE AND PHENOMENOLOGY IN JACQUES DERRIDA}

Here we expose the relationship between the thoughts of the philosopher Jacques Derrida about literature and transcendental phenomenology. We introduce this relationship from the reception of two authors who address Derrida on the literary field in the United States. They seem to assume that Derrida takes distance from philosophy or, at least, from Husserl's philosophy. Reading an unpublished seminar, we begin by posing the problem of literature's historicity. Because this problem is inseparable from a certain power of fiction associated with both, the law and the modern idea of democracy, we show secondly, the idea of literature as a "fictional institution." This idea is developed in relation to a "nonthetic experience of the thesis" linked to the Husserlian transcendental reduction. Finally, we select two moments from the book The Give of Death in which this experience is equivalent to the public, ethicalpolitical experience of a certain secret.

KEYWORDs: Literature, Phenomenology, Fiction, Institution, Public space.

Recepción: 18/11/2019

Aprobación: 14/01/2020

A Camilo González Villanueva

\section{INTRODUCCIÓN}

A comienzos de los años 90 son publicadas dos antologías en los Estados Unidos que reúnen los trabajos del filósofo Jacques Derrida. Sus editores proceden ambos del campo de la literatura, de la francesa y de la inglesa. Pero son heterogéneas. La primera, publicada en 1991 en Columbia University Press, se titula A Derrida Reader. Between the Blinds, y es editada, con una introducción y notas, por Peggy Kamuf. Esta antología, muy especial, no reúne solo textos de Derrida dedicados a la llamada "literatura". Ofrece una selección de fragmentos muy representativos de sus trabajos desde mediados de los años 60 hasta comienzos de los 80, en una secuencia no solo cronológica, sino también temática. La segunda antología, publicada en 1992 en Routledge, Acts of Literature, es editada por Derek Attridge y contiene sobre todo textos dedicados a la literatura. Este texto comienza con una entrevista entre Attridge y Derrida intitulada "This Strange Institution Called Literature", datada en $1989^{2}$. Ambas antologías parecen suponer una

2 En adelante: Esa extraña institución llamada literatura. 
toma de distancia por parte de Derrida con respecto a la filosofía en general o a la fenomenología en particular.

Y no sin razón. Por ejemplo, si se sigue por ejemplo la lectura derridiana de Mallarmé en torno al problema de la mimesis en La diseminación. Allí el Mimo, que no imita nada, es el trabajo de una ficción sin imaginario, de un himen que amenaza la posibilidad de discernir lo imitante de lo imitado, supuesto clásico de la teoría de la mimesis. En una alusión perpetua, esta mimesis rompe con el referente sin romper con la referencia, siendo de ese modo ya no sumiso al orden filosófico de la verdad ( $C f$. Derrida, La diseminación 319). Aclarando el espacio, remarcándolo, espaciándolo, suprime la exterioridad y la anterioridad de lo imitado, de lo significado o de la cosa (Cf. 288). Esta supresión del exterior no da lugar a ningún interior mental, imaginario. Porque no se trata ya de ninguna interiorización del texto en el libro, ni del libro en lo mental, con lo espacioso de la escritura o del texto mallarmeano (así en el "repliegue del blanco" 395) es amenazado todo tematismo, todo sentido o significado en general, sea dialéctico, hermenéutico o fenomenológico ( $C f$. 374). Así, la escritura literaria de Mallarmé aparece en La diseminación muy claramente confrontado con la filosofía, y en consecuencia también, con la fenomenología.

Siguiendo esta confrontación, se podría bien suponer que con esta deconstrucción mallarmeana de la teoría de la mimesis, Derrida parece muy dispuesto a despedirse del racionalismo filosófico, por ejemplo, de un Husserl, a favor de una relación con la literatura. Lo primero parece harto evidente. No dejaremos de confirmarlo aquí. Lo segundo, sin embargo, no resulta evidente. Lo que se dice en La diseminación del espaciamiento que suprime la exterioridad no dando lugar a ningún interior imaginario, se había dicho ya en La escritura y la diferencia contra el enfoque estético, el estructuralismo literario y su antecedente fenomenológico. En esta discusión, en efecto, "el Libro irrealizado por Mallarmé" ha "irrealizado la unidad del Libro", no aparece, como en Platón, como un volumen psíquico, sino como la implicación del volumen, como "todo lo que en la significación no puede estar expuesto en la simultaneidad de una forma" (Derrida, La escritura 39). Contra el esquema teleológico percibido y preestablecido en esta simultaneidad, Derrida va a poner de relieve ese "tomar sentido" en la anticipación de su telos; apertura que libera el tiempo y la génesis. En el infinito reenvío a sí del texto literario, cuyo afuera o referencia no es más que un efecto de texto, la práctica celosa de la literatura, como Derrida lo expone en el seminario inédito Littérature et vérité (1968-1969), no puede ya dominar su apertura. 
Pero, de La escritura y la diferencia a La diseminación también comenzamos a reconocer el pensamiento derridiano de una literatura sin condición, elaborado sobre la base de una articulación con la problemática fenomenológica de una historicidad interna o intrínseca en y más allá de los términos en que Husserl ha querido plantearla ${ }^{3}$. Pero dejemos esto por el momento.

Lo que vuelve especial la antología de Kamuf es que está construida sobre el motivo de la jalousie, palabra que en francés designa tanto los celos (que en castellano se suelen nombrar en plural) como la celosía (en inglés jalousie o Blinds: persianas). Es lo que se ve ya, muy gráficamente, desde la portada del libro. Y es también lo que estructura su larga introducción y la presentación de cada una de sus partes. Una serie de celos, entonces. Finalizando la introducción encontramos estas palabras al lector:

Estos textos ya han pasado por el filtro de otro idioma. Y debido a que Derrida es un idioma celoso, mucho se habrá filtrado u ocultado a la vista. Pero acoja con beneplácito esta limitación como una oportunidad para abrir los postigos y las persianas del pensamiento a lo que viene de su otro, más allá de cualquier lenguaje o idioma. Deja que tu idioma juegue en la luz oblicua. Quien dijo que las cosas más serias siempre deben ser tratadas gravemente, sombríamente, a puerta cerrada, probablemente temía dejar que cierto juego necesario salga a la luz en lo serio. Escucha la risa de Colombine (Kamuf XIII; la traducción es nuestra).

Colombine, como se sabe, es un personaje de "Pierrot asesino de su mujer", mimodrama comentado por Mallarmé en "Mímica". Como se sabe también, ya lo hemos señalado, Derrida se dedica a Mallarmé sobre todo en La diseminación. Lo que no se sabe bien, o no siempre de modo suficiente, es que, a pie de página, en "La doble sesión", se anuncia una publicación bajo el título "Entre dos golpes de dados" (Entre deux coups de dés), en donde el motivo de la jalousie es preponderante ( $C f$. Derrida, Littérature sesión 5 ). Se despliega allí cierta historia del concepto de mimesis entre Platón y Mallarmé. Se analizan los antecedentes clásicos del concepto moderno, crítico y teórico,

3 Hemos intentado hacer este reconocimiento en Trujillo 2017. La problemática de una historicidad interna (o intrínseca) en relación con la obra literaria se la encuentra en Derrida 1989, 25. Antes de eso se la encuentra en Derrida 1962, 94. 
de literatura. Es la historia entre literatura y verdad, la historia de los celos o la envidia de un phyein (crecer, dar a luz) que el filósofo, y, en general, el teórico o crítico de la literatura, escritor o filósofo profesional (Derrida insiste en la filiación filosófica del crítico o del teórico de la literatura), no parece sino ver desde después, en tanto que obra ya conclusa, como mimesis, como repetición, es decir, también, como a un antes o a un pasado que ya no se podrá hacer nunca presente. En un momento radical de este análisis, la mimesis aparecerá como un pliegue de la physis, abriéndose así una relación con el pasado en medio de lo que se supone es lo originario o lo imitado. Y si a partir de Mallarmé la problemática de la mimesis es la del himen que guarda celosamente la referencia, el fuera-de-texto, en la transparencia celosa de su tela, entonces la ficción sin imaginario de la que habla Derrida, ni exterior ni interior, puede todavía ser pensada como una epojé fenomenológica que, suspendiendo el referente, pero guardando la referencia, puede escapar a todo cierre ideal del campo literario no borrando ya la huella del texto.

Visto lo literario desde este pensamiento de los celos de la literatura, de los celos de ella que ella también tiene de sí misma, se podría decir quizá que son siempre celos fuera-del-libro. A condición de entender que con este afuera no se trata ya ni de un referente ni de un interior de tipo psicológico. Lo que está en juego es la posibilidad de que no haya esencia de la literatura. Es lo que con Derrida explicamos en el presente artículo. Si el libro de Kamuf, libro celoso, tiene así un fuera-de-libro que habría que hacer notar o remarcar, su nombre es quizá tanto la fenomenología husserliana como el uso derridiano de la fenomenología husserliana o del método trascendental. Y que este fuera-de-libro no sea simplemente externo a la escritura de su libro, es quizá un formidable desafío de lectura que deja este celoso libro de Kamuf y el problema de los celos de la literatura.

Hasta cierto punto no podía ser de otro modo. En el momento mismo en el que Kamuf cerraba el libro publicándolo, Derrida publicaba en Francia su Memoria de 1953-1954: Le problème de la genèse dans la philosophie de Husserl, hasta ese momento muy desconocido. Kamuf había comenzado su antología con La voz y el fenómeno y porque también contaba con la traducción al francés e introducción de Derrida al Origen de la Geometría de Husserl, su propuesta de antología no le impedía comenzar por el primero, lo que hizo, y tan solo limitándose a hacer algunas alusiones al segundo. Este ha sido un modo de proceder muy expeditivo y no poco usual en el campo 
literario norteamericano. Todo comienza despidiéndose de Husserl a partir de la problemática de la huella ${ }^{4}$.

Pero la omisión de la fenomenología de Husserl es más profunda. Antes del 1962 y publicado solo en 1967, hay también un texto sobre Husserl, el más antiguo de los textos recogidos en La escritura y la diferencia, que Kamuf simplemente omitió: "Génesis y estructura'y la fenomenología" (conferencia de 1959). Kamuf repasa cada uno de los autores abordados por Derrida ("Michel Foucault, Edmond Jabès, Emmanuel Lévinas, Antonin Artaud, Freud, Georges Bataille, Claude Lévi-Strauss"), sin mencionar a Husserl (Cf. Kamuf 4) $)^{5}$. Lo que al parecer no podía entonces ser de otro modo en 1990 (no conocer los alcances de la Memoria de Derrida publicada ese año), habría podido ser de otro modo a través del texto de 1967, salvo por la decisión de Kamuf. El problema de esta decisión es temible porque no se restringe solo a Husserl. Bajo este nombre hay que incluir al Husserl de Derrida y el uso derridiano de la fenomenología trascendental. Y esto temible es también paradójico porque, si lo que hace Derrida lo hace con Husserl, entonces Kamuf no puede borrar el nombre de Husserl del pensamiento derridiano. Y sobre todo no puede hacerlo si lo que hace Derrida con Husserl lo hace también con la literatura.

La entrevista que preside la antología editada por Attridge, está datada en 1989. Es decir, a un año que Derrida publique su Memoria. Es probable que él no la haya conocido. En esta entrevista, Derrida habla de la literatura como "institución ficticia" en términos fenomenológicos. Utiliza esta expresión una sola vez, pero una vez más al menos insiste en esta idea para señalar no solo el poder de ésta para sortear la institucionalidad misma sobre la base de un cierto salvajismo, sino también para señalar su intrínseca historicidad. Porque histórica de lado a lado, resulta imposible reivindicar una esencia de la literatura

$4 \quad$ Se podría consultar Culler, 1982; también Miller, 2001. En un texto en preparación intentamos proponer una lectura de esta recepción no ajena a ciertos motivos nacionalistas, sin dejar de apoyarnos en los seminarios de Derrida dedicados al nacionalismo filosófico (alemán, judeo-alemán, germano-franco-americano) en el curso de los años 80, en particular en su seminario Nationalité et nationalisme philosophiques (Derrida 1984-1989).

En la página 602 de su antología, al momento de señalar brevemente el contenido de cada uno de los textos que componen La escritura y la diferencia, Kamuf confunde el título del texto de Derrida dedicado a la fenomenología husserliana con el título del libro de Jean Hyppolite dedicado a la Fenomenología del espiritu de Hegel: "on the French interpretation of Hegel's Phenomenology of Mind ("'Genesis and Structure' and Phenomenology”). 
o una autonomía sin explicarse con el derecho, sus instituciones modernas, con la institución universitaria y con la idea moderna de democracia. Bajo el concepto de "literariedad", esta difícil existencia y determinación de lo literario recibirá allí mismo una mayor explicitación en lenguaje fenomenológico. Se hablará de nóesis, de nóema y de reducción, sin dejar de observar que la ficción literaria no deja de cuestionar los supuestos mismos tanto de la institución como de la fenomenología. Pero el lenguaje fenomenológico aquí utilizado parece ya sensible al problema literario. Lo que se llamará una "experiencia no tética de la tesis", relacionada con el carácter literario de un texto, implicará, de un lado, la posibilidad de la lectura trascendente de un texto, es decir, una lectura no confinada en el supuesto idealizante de una clausura literaria, y de otro lado, la suspensión de la tesis de la lectura trascendente que, sin negar lo trascendente, hace que lo literario pueda ya no tener lugar, o un lugar determinado. Es la marca de la historicidad de la literatura. Que lo literario no tenga un lugar, o un lugar determinado, pero sin anular la lectura trascendente, es reconocer que hay la huella del texto que no deja encerrar lo literario en "la" literatura.

En este sentido, partiendo por reconocer que la literatura es una institución moderna europea indisociable de la institución del derecho y de la idea de democracia, que es asimismo una institución ficticia que transgrede los límites institucionales y en primer término los de la literatura misma, y por consiguiente, reconociendo también que la obra literaria tiene una relación singular con el espacio público, una relación de responsabilidad, de irresponsabilidad y de perdón por un cierto secreto, se podrá también reconocer en qué medida ella mantiene una relación con la larga tradición bíblica común a las religiones judía, cristiana y musulmana.

\section{LA LITERATURA, SI HAY: FICCIÓN E HISTORIA}

En su seminario Du droit à la littérature, de 1979, a partir del hecho de que se habla de literatura, Jacques Derrida examinará, bajo la locución "si hay" ( $s$ 'il y en a), el carácter problemático de la literatura o fenómeno literario en su pretensión a existir, como un hecho asegurado. "Parto solo del hecho de que se habla de literatura, que hay un nombre 'literatura', que algo se llama 'literatura”" (Derrida, Du droit sesión 1, 1). Tras preguntar “¿cuáles son las condiciones y con qué derechos se habla de literatura?”, dirá: 
Nuestra pregunta no trata con la literatura como un hecho asegurado, sino como con una pretensión problemática a la existencia o a la diferencia específica [comme à une prétention problématique à l'existence ou à la différence spécifique]. El carácter problemático consiste, ante todo, en el hecho de que la literatura, si hay [s'il y en a], si hubiera [s 'il y en avait], tendría una relación complemente singular, y verdaderamente única, con la realidad, con la ficción, con la verdad y sobre todo con el lenguaje (sesión 1,2) (La traducción es nuestra).

De un modo en principio muy empírico, o neutral, se parte entonces del hecho que se habla de literatura, no de que haya o exista ${ }^{6}$. De un modo en principio empírico, digo. O neutral. Pero en su Introducción al Origen de la geometría de Husserl, Derrida dirá que el objeto ideal que es la palabra (mot) supone "una neutralización espontánea de la existencia fáctica" (Derrida, "Introduction" 58). El habla (parole), agrega, es "la práctica de una eidética inmediata", y una "neutralización lingüística de la existencia" es algo que es común a Husserl, a Mallarmé, a Valery y, sobre todo, se encuentra en $\mathrm{Hegel}^{7}$. La única novedad, en Husserl, es que tiene un sentido técnico. No se trata entonces de simple neutralidad, sino de neutralización o de suspensión. Cierta suspensión de lo fáctico (cosa o imagen psíquica) está implicada en este recurso aparentemente empírico a la palabra, pero que no deja de contar con el supuesto suspendido de la existencia ${ }^{8}$.

Dicho de otra manera: se cuenta con la referencia y no con el hecho asegurado del referente, para decirlo en los términos de La diseminación. Ahora bien, una vez que la referencia no implica necesariamente la existencia de su referente, de la que, no obstante, sigue dependiendo, es que parece válido preguntarse o cuestionarse cuáles son las condiciones y con qué derecho se habla de literatura bajo la demanda de referente o de existencia. Comenzar por el hecho de que se habla de literatura, no es partir haciendo una denuncia o un reproche a su pretensión a la existencia autónoma, sino partir tomando en cuenta que se puede pretender eso estando en medio de la suspensión de la referencia que es la palabra.

$6 \quad$ Vale la pena recordar tres cosas: 1. es también el modo de proceder en Canallas (Derrida 2003) a propósito de la democracia; 2. en este modo de proceder está implicada la cuestión de su recepción y de su herencia; y también, 3. la cuestión de su concepto.

Ver nota 1 de Derrida, "Introduction" 58.

8 Veremos más adelante que este aspecto será decisivo para la experiencia de lo literario. 
Si preguntamos ahora por qué resulta problemática la pretensión a la existencia de la literatura, Derrida parece suministrar dos razones. Ambas a la vez históricas y no históricas. Por un lado, porque la pretensión del fenómeno literario a su existencia y a su diferencia específica, a su autonomía de pleno de derecho, ha supuesto una relación no extrínseca sino intrínseca con el derecho (autonomía como auto-nomía) ${ }^{9}$. Es lo que Derrida no dejará de mostrar en su seminario, en el sentido de que lo que se llama literatura mantiene una relación con un "sistema jurídico que establece en el derecho positivo los derechos de autor, la propiedad, la originalidad, la función de títulos, etc., brevemente, todo lo que vuelve posible lo que se identifica bajo el nombre de obras literarias firmadas, idénticas a sí mismas, clasificables, públicas, garantizadas y controladas, etc." (Derrida, Du droit, sesión 1, 10). Pero también, y en la medida en que esa relación entre el derecho y lo que se llama literatura no se da sin la universidad, cierta naturalización tiene lugar

sin reflexionar, o en todo caso, sin tematizar, sin hacer de eso un tema de reflexión problemática, toda la sistematicidad jurídica en curso de constitución y concerniente a los derechos de autor, la propiedad de una obra, sus contornos de identificación, la evaluación de su originalidad, las condiciones y los límites de su reproducción total o parcial, todo lo que tiende a su publicidad, al hecho que una obra pública y firmada deba plegarse a ciertas condiciones (veremos cuáles), sin tematizar ni problematizar esta legislación reciente o en curso de constitución, la institución universitaria que pretendiera hacer de las obras literarias su objeto, se construirá sobre o en acuerdo no declarado (naturalizado, como si esta legislación fuera natural o ahistórica) con este estado del derecho, sin reflexionarlo lo acompañará como su correspondiente solidario. Y lo hará no solo para las producciones 'modernas', contemporáneas de esta universidad, sino a veces proyectando retrospectivamente todas las evaluaciones, las conceptualizaciones, las puestas en perspectivas sobre 'obras' de otras épocas” (sesión 1, 10). (La traducción es nuestra).

9 Vale la pena recordar que, en un giro similar al título del seminario de 1979 que comentamos, la primera parte del libro Force de loi se intitula "Du droit à la justice", y constituye la conferencia de apertura en un coloquio de 1989 "Deconstruction and the Possibility of Justice" que reunió a filósofos, juristas y teóricos de la literatura. $C f$. Derrida, Force de Loi. 
Universidad, derecho y literatura son sistemas "o estados de sistema que tienen una relación interna y esencial, se constituyen tal y como los conocemos bajo las forma y nombres que les damos hoy a fines del siglo XVIII y a comienzos del XIX" (sesión 1, 10). Por esta articulación jurídica y política de la literatura, en un proceso de autonomización en la que ella no ha estado fuera de la ley, ella no ha dejado de pensarse en relación con la democracia. En el seminario se muestra, a través de varios ejemplos, la manera en que el modelo democrático domina la representación de su autonomía ${ }^{10}$. Eso de un lado.

Lo problemático de la pretensión por una existencia asegurada se debe también, de otro lado, a que lo que se llama literatura tiene que relacionarse a su vez con "una especie de ficcionalidad de la jurisdicción" en la medida en que la posibilidad de la ficción, "y quizá por consiguiente una cierta posibilidad de la literatura", parece estar implicada en el origen del derecho (se hace referencia aquí a la jurisdicción como juris-dicción) ${ }^{11}$. En efecto,

si en el origen del derecho, del discurso diciendo o significando el derecho, hubiera algo como una ficción o una convención implicando una ficción, o una performance produciendo su propia referencia, ¿no es algo como la literatura o al menos como la posibilidad de la literatura -que no es necesario confundir demasiado rápido, por supuesto, con el hecho o fenómeno literario- no es algo como la posibilidad [destacado a lápiz por el autor] de la literatura, que tendría una parte en el origen del derecho mismo? No es solo una cuestión DE [sic] derecho que plantearemos a la literatura desde el derecho, estudiando las condiciones jurídicas que harían posible la literatura; es también la cuestión DEL [sic] derecho que plantearemos desde la literatura; plantearemos la pregunta de la literatura al derecho (au droit) (sesión 1,6) (La traducción es nuestra).

$10 \quad$ El texto aclara: “Aunque República no quiere decir democracia, en el caso de la llamada "República de la Letras" (desde fines del siglo XVII y durante todo el XVIII; también Commonwealth of Literature, República literaria), muy rápido se concibe esta cité, esta política, esta res publica como una democracia, una democracia crítica donde el derecho de decir, de juzgar, de enunciar juicios es sin límite e igualmente compartido. Así en D'Alambert, Hodard de la Motte, Guillaume-Alexandre de Méhégan, Etienne Fourmond" (sesión 1, 11).

$11 \quad C f$. el seminario Le respect (1980-1981). También, Derrida, Prejugés. 
Esta segunda razón obliga a relacionar lo que se llama literatura con algo que es como ella, que no habría que confundir con ella y que también está relacionado con el derecho.

Lo problemático entonces, de uno al otro lado, no es solo que, en su pretensión a existir de derecho, el derecho forme parte del derecho a la literatura de su autonomía, sino también que en dicha pretensión ella se relaciona con algo como ella, con una cierta ficcionalidad, con una performance que produce su propia referencia, y que está tanto en el origen del derecho mismo como en su propia posibilidad. Es esta una hipótesis sobre la relación entre la historia y una ficción en general, o sobre una ficcionalidad relacionada con la historia que, si no se deja elaborar bajo el nombre de una especie de "ficción histórica", sin duda obliga a reelaborar el concepto de historia sobre la base de un concepto más general de ficción, tal y como es aquí sugerido.

En todo caso, tomado en cuenta la historicidad de la literatura a partir de este doble supuesto (lo llamo así provisoriamente), podemos comenzar a entender que Derrida utilice la locución "si hay", en el sentido privativo pero condicional de que ella, la literatura, pueda no existir, no tener lugar. Pero también, bajo la misma locución, en el sentido incalculable e incondicional, de un "si se da" (es gibt). Es en relación con esta ficcionalidad, que mantiene a la literatura en souffrance, tal su pasión, como veremos enseguida, que Derrida formulará la hipótesis de su seminario diciendo que la literatura (esta vez no la "llamada" literatura) atraviesa o "se confunde con un proceso de autonomización" del que forma parte "el acontecimiento por el cual la literatura se nombra [se nomme], se llama a sí misma [s'appelle ellememe], se autonombra [s'autonomme] al mismo tiempo que se autonomiza [s'autonomise] y tiene la pretensión de nombre propio y propiedad" (sesión $3,7)$. El acontecimiento de su auto-nombramiento forma parte del proceso de auto-nomización. Es por tanto el problema de la ley y del nombre propio como problema del tener lugar de la literatura, de su "ha lugar" en su nombre.

No se puede asegurar la existencia, su derecho a la existencia autónoma de la literatura, porque de un lado, mantiene una relación intrínseca con el derecho, y de otro, ambos dependen de una cierta ficcionalidad. Desde que hablamos, nombramos la literatura, no se puede asegurar su existencia autónoma sin afirmar a la vez su intrínseca y esencial relación con el derecho y con una ficcionalidad del derecho que es también su posibilidad. Casi terminando Esa extraña institución llamada literatura, Derrida hablará de "un poder" que, en una entrevista con Roudinesco, llamará "un poder de ficción", y que relaciona derecho y literatura, distinguiendo sin embargo 
el alcance de dicho poder en ambos ( $C f$. Derrida / Roudinesco, $Y$ mañana $q u e ́)$. Acabando de afirmar, en primer lugar, la necesaria distinción entre la ficción en general implicada en lo que llama "la estructura de la textualidad en general" y, por ejemplo, la ficción de la literatura donde además no todo en literatura es estrictamente del orden de la ficción, procede enseguida a plantear la posibilidad de que la literatura no sea simplemente un ejemplo, un efecto o una región entre otras de dicha textualidad (hay aquí cierta diferencia declarada con Rodolphe Gasché, a la que volveré más adelante). Es lo que sucedería en la época moderna, donde la escritura literaria parece ofrecer un "hilo conductor privilegiado" para acceder a la estructura general de la textualidad. Y esto debido a que "detenta un poder revelador que ciertamente no es el único, que puede compartir hasta cierto punto con el derecho, por ejemplo, con el lenguaje jurídico, pero que en una situación histórica dada (la nuestra, precisamente, y he aquí una razón más para sentirse provocado, convocado por la 'cuestión de la literatura'), nos enseña más, e incluso lo 'esencial', acerca de la escritura en general..." (Derrida, Esa extraña 148; $c f$. Derrida, Cette étrange 289) ${ }^{12}$. Y casi enseguida, tras señalar que la literatura "no es una institución entre otras o como las otras", se va a decir que

aunque la literatura comparta un cierto poder y un cierto destino con la 'jurisdicción', con la producción jurídico-política de fundamentos institucionales, de constituciones de Estados, de legislación fundamental, e incluso con los actos performativos teológico-jurídicos que se encuentran en el origen de la ley, en un cierto punto también puede excederlos, interrogarlos, 'ficcionalizarlos' (148; traducción ligeramente modificada; $c f .290$ ).

\section{UNA EXPERIENCIA NO TÉTICA DE LA TESIS: LA ANARQUÍA DE LO LITERARIO}

¿Tendría que sorprendernos que en la entrevista entre Attridge y Derrida el papel de la fenomenología sea tan importante? Creemos que no. Y esto no solo por la coyuntura que yo señalaba en el sentido de que 1989 es un contexto en el que Derrida ha estado en el proceso de reedición y está a un año de publicar

12 En adelante citamos dando primero el número de página de la traducción en castellano y enseguida el número correspondiente del texto en francés. 
su Memoria en 1990, sino porque ha insistido desde temprano y a lo largo de todo su trabajo sobre su relación con la fenomenología trascendental ${ }^{13}$. Sin embargo, la publicación de su Memoria parece haber logrado poner su relación con Husserl en un importante relieve ${ }^{14}$. Destacamos que en una entrevista con Antonie Spire, iPalabra!, no solo dice sentirse inquieto y con una cierta mala conciencia con respecto a su distancia con Husserl $(C f$. Derrida, ;Palabra! 84), sino que también señala allí que cuando se trata de deshacerse de sedimentaciones especulativas y teóricas, de librarse de presuposiciones filosóficas, la fenomenología "siempre es el recurso de la deconstrucción", y que incluso es lo que hace que la deconstrucción "fuera a la vez un gesto fenomenológico" (84). Agrego de paso, que frases tales como "la suspensión" de la "tesis del sentido determinado o del referente real" y de "la virtud propiamente fenomenológica, por consiguiente, meteórica, del fenómeno literario", todas ellas en Dar la muerte (Derrida, Dar la muerte 206), pueden también ser expresión de este relieve aparentemente relacionado con la publicación de 1990. Volveré sobre esta referencia en el último punto de este artículo.

Si el recurso explícito a la fenomenología trascendental es algo con lo cual Derrida enfrenta el problema de una textualidad general y de un poder de ficción del que la literatura no solo no es simplemente un ejemplo, un efecto o una región entre otras, entonces la distancia representada por Derrida con respecto al supuesto interés primario por la literatura antes que por la filosofía, expresada en la entrevista con Attridge ${ }^{15}$, quizá encuentra una cierta confirmación en la entrevista con Spire en la forma del remordimiento arriba señalado con respecto a su distancia de Husserl. Y dado que es el supuesto de un interés primario por la literatura lo que podría estar en el fondo de

13 Por ejemplo, en ese alusivo pasaje en De la gramatología, en el que dice que "un pensamiento de la huella no puede ya romper con una fenomenología trascendental ni reducirse a ella" (Derrida, De la grammatologie 91).

$14 \quad$ Así por ejemplo, en Le Toucher, refiere a "la ley del phainesthai" (Derrida, Le Toucher 257), siendo su primera versión de 1992; también en Espectros de Marx, a propósito de la espectralidad y la "anarquía del nóema” (Derrida, Espectros 215).

15 Es la primera pregunta. Attridge: “¿Podría desarrollar esa afirmación concerniente a su interés primario [primary interest] por la literatura, y decir qué relación guarda este con su amplio trabajo sobre textos filosóficos?”. Derrida: “QQué puede ser un "primary interest”? Jamás me atrevería a decir que mi interés primario apunta a la literatura antes que a la filosofía. Aquí la anamnesis sería arriesgada, pues me gustaría escapar a mis propios estereotipos" (Derrida y Atttridge 115). 
este asunto, nos preguntamos si es la lectura derridiana de Mallarmé lo que en gran medida ha contribuido a polarizar dicho supuesto allí donde parece insistirse en lo inaccesible que a la fenomenología le resulta el espacio literario mallarmeano, dejando quizá la impresión que la deconstrucción derridiana se había despedido de Husserl, por no hablar de Hegel, y en general, de la tradición filosófica europeo-continental. Aquí habría que comprometerse con cierta demostración. Pero no nos agotamos en ello. Nos limitamos a decir que quizá por eso mismo, en los Estados Unidos, a mediados de los años 80, fue Rodolphe Gasché, en Le Tain de Miroir, quien quiso poner de relieve, en relación con Mallarmé, el uso derridiano de la fenomenología, hablando entonces de un cierto "carácter epojal de la 'literatura' misma":

En un movimiento que parece confundirse con una reducción trascendental fenomenológica en la que la literatura está sometida a una especie de epojé, poniendo entre paréntesis sus determinaciones mimetológicas o formalistas, Derrida, más que producir la esperada esencia de la literatura, abre a una estructura radicalmente no fenomenologizable. Pero esta puesta entre paréntesis revela lo que llamaría el carácter 'epojal' de la 'literatura' misma (248) (La traducción es nuestra).

Bajo el influjo de esta epojé, esta "literatura" entre comillas, correspondería, según Gasché, a una nueva práctica de escritura y no ya a la literatura entendida como ese género de escritura ligado a la historia de la literatura que es también la historia de la filosofía. Si lo que Derrida llama "el texto general" es para Gasché, "un agente fundador para la filosofía y la literatura en su diferencia" (245), es porque para este último este texto general "no es la literatura" (264).

Ahora bien, los pasajes anteriormente referidos en torno al poder de la literatura, que comparte con lo jurídico-político, ambos relacionados con la ficcionalidad o ficción en general (o textualidad en general) y de la que según Derrida la literatura no sería solo un ejemplo sino un hilo conductor privilegiado, se decía nada menos que en confrontación con esta versión de Gasché de la relación entre la "literatura", o texto general, y la literatura. Si antes solo me limité a mencionar el nombre de Gasché, era porque hacía falta el presente contexto, a saber, la relación entre esa ficcionalidad $y$ la institución, histórica, llamada literatura. Esta relación y su implicación, que faltaría en Gasché, se deja sentir a través del adverbio "también" (aussi) en la entrevista Esa extraña institución llamada literatura. 
Es en el marco de la primera respuesta a Attridge que encontramos la locución "institución ficticia". Tras un recuerdo de juventud, de "obsesión por lo proteiforme", el interés por la literatura ya estaba vinculado, si bien de modo confuso, con el interés por "una extraña institución" que permite decirlo todo y según todas las figuras. Enseguida leemos: "El espacio literario es no solo el de una ficción instituida, sino también [adverbio faltante en el texto] una institución ficticia que en principio permite decirlo todo" (Derrida, Esa extraña, 117, traducción parcialmente modificada; cf. Cette étrange 256). No solo ficción instituida, sino también institución ficticia. La ficción se instituye y se franquea ficticiamente la institución. La posibilidad de decirlo todo es la posibilidad de una dicción interminable y que cruza la ley, su juris-dicción. La institución desbordando la institución. Es lo que se dirá enseguida.

Decirlo todo es, sin duda, reunir traduciendo una en otras todas las figuras, totalizar formalizando, pero decirlo todo es también franquear [franchir] las prohibiciones. Es liberarse [s'affranchir] -en todos los campos en que la ley puede hacer a la ley. La ley de la literatura tiende, en principio, a desafiar o a levantar la ley. Eso permite, por consiguiente, pensar la esencia de la ley en la experiencia de ese 'todo por decir'. Es una institución que tiende a desbordar la institución (117, traducción parcialmente modificada; $c f .256)$.

Un poco después, la literatura como institución histórica, pero también como institución de la ficción. Tras preguntarse, qué es la literatura, leemos: es "la literatura como institución histórica con sus convenciones, reglas, etc., pero también [presente en la traducción] esta institución de la ficción [institution de la fiction] que en principio da el poder de decirlo todo, de liberarse [s'affranchir] de las reglas, de desplazarlas, y por consiguiente de instituir, de inventar e incluso de arrojar sospechas sobre la tradicional diferencia entre naturaleza e institución, naturaleza y ley convencional, naturaleza e historia" $(118 ; c f .257)$. El poder de decirlo todo lo detenta (en cierta afinidad con la soberanía) la institución de la ficción, pero no sin autorización, y también, no sin una relación con el devenir, que es también cierto por-venir, de la idea moderna de democracia.

Necesitaríamos aquí formular interrogantes jurídicas y políticas. La institución de la literatura en Occidente, en su forma relativamente moderna, está ligada a una autorización para decirlo todo y, sin duda también [adverbio faltante en el texto], al devenir de la idea moderna de democracia. No es que dependa de una democracia ya instalada, pero 
me parece inseparable de lo que convoca (appelle) una democracia por venir, en el más abierto y sin duda aún por llegar sentido de democracia" (118, traducción ligeramente modificada; $c f .257)$.

La literatura sería histórica, de lado a lado. Es lo que se va a decir aquí y también en otros lugares (por ejemplo, en la entrevista con Roudinesco ya señalada, pero sobre todo a propósito de Blanchot en Derrida 1998). Lo que se llama literatura, lo que se nombra así, sería así indisociable tanto del derecho (que es también derecho a la literatura) y de la democracia (que es también democracia por venir). Como tal, sería una invención (que es también una ficción) muy reciente. Ni la poesía griega o latina (que pertenece al pasado europeo), ni las obras discursivas no europeas, pertenecería strictu sensu a la literatura. Y si el reciente espacio institucional, o sociopolítico, de producción literaria, afecta en su misma estructura a las obras, por ejemplo, a través de la garantía socio-político-jurídica, de principio, de poder decirlo todo, eso mismo significa que no hay algo así como una esencia de la literatura. Nótese aquí que la radical historicidad de la literatura (ella es afectada en la estructura de sus obras), incluso su circunscripción histórica (ni griega, ni latina, ni no europea), es lo contrario de cualquier afirmación de identidad, de esencia o de existencia, de la literatura. Lo que me interesa hacer notar es que este pensamiento de la historicidad de la literatura es explicado aquí en términos fenomenológicos ${ }^{16}$.

Tras hacer referencia a esa literatura que tiene en común su inscripción "en una experiencia crítica de la literatura" (122; $c f$. 261), a textos que son ellos mismos "una especie de vuelta sobre la institución literaria" ("el fin de la literatura desde Mallarmé a Blanchot", Celan y el "poema absoluto... que no hay"), una pregunta sobre aquello que subvierte una "lectura trascendente" o referencialista de la escritura literaria, lleva a Derrida a explicar qué significa que la "literariedad" (littérarité) no sea la propiedad intrínseca de un texto: "[n]o hay ningún texto que sea literario en sí mismo. La literariedad no es una esencia natural, una propiedad intrínseca de un texto" (124; $c f .263)$. La literariedad es más bien "el correlato de una relación intencional con el texto, una relación intencional que integra en él, como un componente o una capa

16 Aunque tenemos a la vista lo que, según Gasché, "Derrida debe a la fenomenología husserliana" (Gasché 233), nuestro propósito aquí es menos insistir en el alcance de esta deuda filosófica, que cernir el alcance filosófico de su incidencia, en particular en lo que atañe al problema de la relación entre ficción e historia a propósito de la historicidad de la literatura. 
intencional, la conciencia más o menos implícita de reglas convencionales o institucionales, sociales, en cualquier caso" (124, traducción ligeramente modificada; $c f .263-264$ ).

En este recurso a la intencionalidad de la conciencia hecha a base de correlaciones ( $C f$. Derrida, "La phénoménologie"), el aparecer de la literariedad es indisociable de la experiencia de un texto en sí mismo no literario, lo que podríamos tener la tentación de interpretar como el aparecer del núcleo noemático en tanto que indisociable del nóema completo ${ }^{17}$. En todo caso, no puede querer decir que se trata de algo meramente subjetivo, en el sentido de una subjetividad empírica, o de algo arbitrario, sujeto al capricho. Y no puede querer decir tal $\operatorname{cosa}^{18}$ porque la correlación noético-noemática aquí reseñada no solo no puede ser meramente subjetiva, dado que la nóesis es ya en general estructura de sentido o conciencia de algo, sino sobre todo porque hay también, correlativamente, el lado objetivo que es el nóema. Para Derrida el carácter literario de un texto reside en el lado ya más objetivo de la experiencia. "El carácter literario del texto está inscrito del lado del objeto intencional, es su estructura noemática, podría decirse, y no solo del lado subjetivo del acto noético" (124; cf. 264).

La experiencia de lo literario es una experiencia del texto "en" el cual hay rasgos que convocan (appellent) a la lectura literaria no sin evocar (rappeller) la convención, la institución o la historia de la literatura. Hay una historicidad del llamado. Y si esta experiencia objetiva de lo literario es la experiencia de una subjetividad no empírica y enlazada con una comunidad intersubjetiva y trascendente, entonces hay que tener presente que la estructura

17 Pondremos enseguida en tela de juicio lo que acabamos de decir a la vista de una cierta "anarquía del nóema". En todo, caso, en su "Introducción" al Origen de la geometría de Husserl encontramos en Derrida una comparación entre el núcleo unitario del sentido noemático que puede ser mentado según diversos modos intencionales con vistas al pleno noema y la identidad ideal de la significación que se vuelve accesible en varias lenguas y que admite traducción. Derrida "Introduction", 62, nota. En cuanto al núcleo y al pleno nóema en Husserl, cf. Husserl Ideas I, 220ss.

18 Esta aclaración parece ser análoga a aquella que tiene lugar en el momento en que, contra el enfoque estético de la obra literaria que hace como si la obra no tuviera origen, Derrida señala la necesidad de atender a "la historicidad intrínseca de la obra misma", aclarando que se relaciona con "un origen subjetivo que no es simplemente psicológico o mental" (Derrida, La escritura, 25). 
noemática está incluida a título no "real" (reell) en dicha subjetividad ${ }^{19}$. Como componente intencional, no solo no pertenece a lo real-empírico (fáctico o mundano), sino que tampoco a lo real-conciencia (material o hylético), es decir a la subjetividad misma. Como nóema, la literariedad es irregional, es decir anárquica ${ }^{20}$.

Entonces, si de un lado la posibilidad de no poder prescindir de la lectura trascendente va a depender de la suspensión de la no-experiencia que se tiene de lo literario, es decir de la tesis (en "actitud natural" en el decir de Husserl) de un ser literario con prescindencia de la experiencia, de otro lado, es también una experiencia no tética de la tesis, es decir que solamente suspende el referente literario no la referencialidad. Por esta suspensión lo literario puede aparecer en todas partes en que su experiencia pueda no tener ya un lugar determinado, o una posición determinada ${ }^{21}$.

Sin suspender la lectura trascendente, pero cambiando la propia actitud con respecto al texto, uno puede siempre reinscribir en un espacio literario cualquier declaración, un artículo de periódico, un teorema científico, un fragmento de conversación. Hay, entonces, un funcionamiento literario $y$ una intencionalidad literaria, una experiencia más que una esencia de la literatura (natural y ahistórica). La esencia

19 En dicho enlace, nos parece que la noematicidad es la experiencia subjetiva que sitúa a la literatura tanto en lo trascendental como en la trascendentalidad de la abertura, es decir como literariedad. Cf. Derrida, La escritura, 224.

20 De la "anarquía del nóema" se habla más tempranamente en "“Génesis y estructura' y la fenomenología”, en La escritura y la diferencia. Se explica allí que entre los momentos intencionales de la conciencia que son la nóesis y el nóema, este último no pertenece propiamente a la subjetividad. "Hay en la conciencia en general una instancia que no le pertenece realmente". Esta inclusión no real (alemán: reell) del nóema, esto es "de la objetividad del objeto, el sentido y el 'como tal' de la cosa para la conciencia", que no es tampoco la cosa determinada en su existencia salvaje, es la "anarquía del nóema": "la raíz y la posibilidad misma de la objetividad y del sentido" (Cf. Derrida, La escritura 224).

21 Hay que tomar en cuenta dos cosas: 1. como lo ha hecho notar Derrida en su Memoria, la génesis del nóema tiene lugar a partir del objeto real (réel) pasivamente acogido. 2. Como lo ha hecho notar en "'Génesis y estructura' y la fenomenología”, mientras que el nóema "es un componente intencional y no-real, la hylé es un componente real pero no-intencional de la vivencia. Es la materia sensible (vivida y no real) del afecto antes de toda animación mediante la forma intencional. Es el polo de pasividad pura, de esta no-intencionalidad sin la que la conciencia no recibiría nada que fuese otro que ella, ni podría ejercer su actividad intencional. Para la primera referencia, ver Derrida, Le problème 152. Para la segunda, ver Derrida, La escritura 224-225. 
de la literatura, si insistimos en esta palabra, esencia, es producida como un conjunto de reglas objetivas en una historia original de los 'actos' de inscripción y de lectura" (125, traducción parcialmente modificada; $c f .264)$. Quizá por ello la "reducción trascendental", recomendada por Husserl como conversión fenomenológica de la mirada, sea "la condición misma de la literatura" (126; cf. 265).

Más arriba evocábamos ese pasaje de su "Introducción" al Origen de la geometría de Husserl en el que Derrida señalaba la neutralización lingüística de la existencia como un motivo común a Mallarmé, Husserl, Valery y Hegel. En el presente contexto se dirá que tanto la poesía como la literatura poseen el rasgo común de "suspender la ingenuidad tética de la lectura trascendente". Y que, en este sentido, "proveen o facilitan un acceso 'fenomenológico' a lo que hace de una tesis una tesis como tal" (125-126, traducción ligeramente modificada; $c f$. 265). Como "una experiencia 'filosófica' que neutraliza o se neutraliza", la experiencia literaria es la experiencia de una literatura sin condición, o siempre ya condicionada. La experiencia no tética de la tesis lo es de una anarquía en virtud de la cual, como se va a decir en Dar la muerte:

[C]ualquier texto confiado al espacio público, relativamente legible o inteligible, pero cuyo contenido, cuyo sentido, referente, firmante y destinatario, no son realidades plenamente determinables, realidades a la vez no-ficticias o libres de toda ficción, realidades entregadas, como tales, por una intuición, a algún juicio determinante, puede convertirse en una cosa literaria" (123, traducción parcialmente modificada; $c f .175)^{22}$.

Un poco antes, en la entrevista con Attridge, Derrida ha reconocido y justificado el recurso al lenguaje de tipo fenomenológico, incluso si la lectura o la escritura, en particular la literaria, lo pone en crisis como al concepto de institución. En el presente contexto dirá que "llevando esta proposición

22 Cuarenta años antes, en su "Introducción" al Origen de la Geometría de Husserl, Derrida ha señalado la forma fenomenológica de la historicidad y las problemáticas abiertas por ella a propósito de la tradicionalización y mediación del sentido. En relación con la Rückfrage leemos esto: "A partir del documento recibido y ya legible, me es ofrecida la posibilidad de preguntar de nuevo y de vuelta [en retour] por la intención originaria y final de lo que me ha sido entregado por la tradición. Esta, que no es sino la mediatez misma y la apertura a una telecomunicación en general, puede entonces, como dice Husserl, 'dejarse interrogar'" (Derrida, "Introduction" 36). 
a su límite, me sentiría tentado a decir (como he dicho en otro lugar) que el lenguaje fenomenológico con lo que presento todo esto termina desalojado de sus certezas (presencia a sí de la conciencia trascendental absoluta, o del cogito indubitable, etc.) y desalojado justamente por la experiencia extrema de la literatura, o incluso, muy simplemente, de la ficción y el lenguaje" (Derrida, Esa extraña 126, traducción parcialmente modificada; cf. Cette étrange, 265 $)^{23}$.

¿Qué podría significar que la lectura trascendente, que es necesario aquí mantener para que haya experiencia a-tética o sin esencia de lo literario, pueda ya prescindir de la epojé o reducción trascendental? Cuando un texto literario o poético resiste absolutamente a una lectura trascendente, dirá Derrida, "tal tipo de lectura pura y simplemente destruye la huella del texto" (127; cf. 266). Las consecuencias de esto no se harían esperar: una literatura hablando solo de literatura, una obra puramente autorreferencial. Sin embargo, cuando no hay esencia de la literatura, es decir una identidad en sí de la cosa literaria, cuando lo que se promete o se da como literatura nunca se da como tal, dicha autorreferencia es anulada. No puede haber auto-referencia de la literatura si no hay literatura como tal. Aniquilación de la nada "bajo el nombre de literatura". Cerca ella de todo. Quizá, en el borde de todo. Nunca idéntica a sí misma, sin definición, "lo que se anuncia y se rechaza bajo el nombre de literatura no es identificable con ningún otro discurso" (127, ligeramente modificada; $c f$. 267). "Pero si no se abriera" a los otros discursos tampoco sería literatura. "No hay literatura sin una relación suspendida con el sentido y con la referencia. Suspendida, eso quiere decir el suspenso, pero también la dependencia, la condición, la condicionalidad. En su condición suspendida, la literatura solo puede excederse a sí misma" (127, parcialmente modificada; $c f .267)$. Mediante la suspensión o epojé otra literatura parece abrirse, y con ella, también, otra "época" de la literatura.

23 Presencia a sí de la conciencia trascendental absoluta, cogito indubitable, principio de los principios de la fenomenología, reducción privatista, presentificación como derivación de la imaginación, etc., son todos aspectos de la fenomenología husserliana y en tantas partes dentro de los trabajos de Derrida, que es preciso tomar en cuenta para aquilatar bien el uso derridiando de la fenomenología trascendental que aquí observamos. 


\section{LA EPOJÉ Y EL SECRETO: "PERDÓN POR NO QUERER DECIR"}

Acabamos de reconocer que, si bien desalojado de sus certezas, es en lenguaje fenomenológico que la literatura puede explicarse con una textualidad general o un poder de ficción del que no es simplemente una región entre otras. Parafraseando a Derrida y viniendo del seminario Du droit à la littérature a la entrevista Esa extraña institución llamada literatura, podemos entonces decir que, si la literatura nos enseña algo esencial acerca de la escritura en general o del texto en general, es porque no es solo una ficción instituida, sino una institución ficticia. Esta institución que desborda la institución permite, en principio, decirlo todo, su dicción es capaz de cruzar la ley, su juris-dicción.

El poder de la literatura de decirlo todo lo detenta no sin autorización, y también, no sin una relación con el devenir, que es también cierto por-venir de la idea moderna de democracia:

La institución de la literatura en Occidente, en su forma relativamente moderna, está ligada a una autorización para decirlo todo y, sin duda también [adverbio faltante en el texto], al devenir de la idea moderna de democracia. No es que dependa de una democracia ya instalada, pero me parece inseparable de lo que convoca (appelle) una democracia por venir, en el más abierto y sin duda aún por llegar sentido de democracia (118, traducción parcialmente modificada; $c f .257)$.

Lo que se llama literatura, lo que se nombra así, sería entonces indisociable tanto del derecho (de ahí también el derecho a la literatura) y de la democracia (que es también democracia por venir). Como tal, sería una ficción institucional (que es también una institución ficticia) muy reciente, como lo hemos señalado.

Que sea a través del advenimiento de una garantía socio-político-jurídica que ella esté autorizada a decirlo todo, y también a ocultarlo todo, va a implicar, como se dirá en Dar la muerte "una alianza indisoluble entre una autonomía extrema (la libertad democrática de todos y de cada uno, etc.) y una heteronomía extrema" (Derrida, Dar la muerte, 146). Por esta última, ya lo sabemos, ese derecho no escapa a la delimitación de lo literario a partir de criterios externos: "[N]inguna frase es literaria en sí misma, ni devela su 'literariedad' [littérarité] en el transcurso de un análisis interno; no se convierte en literaria, no adquiere su función sino según el contexto y la convención, es decir, desde poderes no literarios" (146-147, traducción parcialmente modificada; $c f$. 208). Por la primera, en virtud de su relación indisociable con la democracia, la obra literaria exonera al firmante de la 
responsabilidad del sentido y del referente ante la ley política y cívica. Es la posibilidad que tiene de no detenerse a plantear ningún sentido ni referente, la posibilidad de no querer decir nada. Pero su responsabilidad se agrava "para con el acontecimiento singular que constituye cada obra" (146) desde el momento en que en dicho acontecimiento literario hay "secretos" o "efectos de secretos encriptados" que ya no tienen que responder a ningún sentido o realidad, que reclaman una "suspensión", es decir "la puesta entre paréntesis o entre comillas de la tesis del sentido determinado o del referente real, de su delimitación; de ahí la virtud propiamente fenomenológica, por consiguiente meteórica, del fenómeno literario" (146).

Epojé y secreto. Los secretos, o efectos de secretos, reclamarían la suspensión, la puesta entre paréntesis o entre comillas de la tesis del sentido determinado o del referente real. Y, ya lo sabemos, no sin mantener la referencia. Es decir, no sin la experiencia a-tética de aquello que se suspende. Cuestión de responsabilidad y de espacio público. Es la posibilidad que tiene la literatura de no querer decir, conferida por su indisociable lazo jurídico y político con la democracia, como posibilidad de exoneración de la responsabilidad del sentido y del referente ante la ley, la política. Por ejemplo, el autor no es el personaje. Puede no ser responsable de los dichos de este último. Que, en sí mismo, no es nada. En otro lugar leemos: "Los personajes de ficción no tienen ninguna consistencia, ningún espesor más allá de su fenómeno literario, la inviolabilidad absoluta del secreto que portan consiste primero en la superficialidad esencial de su fenomenalidad, en lo demasiado evidente que dejan ver" (Derrida, Donner 194). Pero, por lo mismo, hay la hiperresponsabilidad de la literatura para con el acontecimiento singular de la obra que genera dichos efectos. Secretos públicos. Acontecimientos singulares que no tienen lugar. O que no tienen más que lugar. Responsabilidad, entonces, "nula e infinita", "como la de Abraham". En Dar la muerte, Derrida explora una historia santa que la literatura, institución europea moderna, hereda y reniega en su filiación. Su secreto esencial es el momento abrahámico de esta historia. Es también, por lo mismo, la historia de tres religiones del libro de la que la literatura no es en ningún caso ajena: el judaísmo, el cristianismo y el islam. De esta herencia, abordada por Derrida en este libro, nos limitamos a señalar, y a reseñar, sobre todo parafraseando y citando, dos aspectos relativos al secreto y a la epojé o suspensión de la tesis.

Analizando Temor y temblor de Kierkegaard, Derrida habla del deber absoluto hacia Dios que implica una especie de don o de sacrificio, anunciando con ello un dar (la) muerte, y entonces también la literatura. En este deber 
está implicado el relato bíblico del sacrificio de Isaac. Este sacrificio como tesoro común de las tres religiones del libro: el judaísmo, el cristianismo y el islam. Este deber absoluto, de la absoluta responsabilidad, consiste también, paradójicamente, en la exigencia de ser irresponsables, de cometer perjurio con respecto a lo universal, al orden general de la ética y de la ley, a la fenomenalidad de lo público, pero reconociendo, confirmando, reafirmando lo mismo que se sacrifica. Mantiene entonces la referencia. Abraham acepta la petición de Dios de dar muerte a su hijo Isaac y de guardar el secreto. Acepta eso segregándose y sacrificando a su hijo, a su filiación, a su descendencia y a Dios mismo que le ha pedido poblar la tierra con su descendencia. Abraham pide perdón. Perdón por no querer decir.

Es que el deber absoluto en nombre de Dios es el deber para con el radicalmente otro que debe permanecer trascendente, oculto, secreto, y que demanda guardar el secreto, secreto esencial para ejercer la responsabilidad absoluta como responsabilidad sacrificial. Observa Derrida que Abraham es fiel a Dios en la traición a todos los suyos. El vínculo de nuestra singularidad con la singularidad absoluta del otro que es Dios comporta el riesgo de sacrificio absoluto en el que están implicados una generalidad innumerable de otros. El alcance de este secreto esencial es tal que el hecho mismo de que Dios decida suspender o interrumpir el proceso sacrificial de Isaac, no impide que ya haya tenido lugar. Dios decide suspenderlo en el instante en que ya no hay tiempo. Suspendido el cuchillo en el aire, es ya el instante del dar (la) muerte, y también del dar (la) muerte de cada instante.

Ahora bien, Derrida insistirá en que la respuesta absoluta a Dios y ante Dios rompe con el saber, con la manifestación, con lo fenoménico. Lo que va a implicar que no va a haber generalidad ética que no sea víctima de la paradoja de Abraham. En un cruce entre Kierkegaard y Lévinas a través de Husserl, se va a decir que esta ruptura será nuestra experiencia del otro, del otro de "cada uno de nosotros". Es lo que lo que volverá legible la relación con lo ilegible. Se comienza por decir que Dios es "la figura o el nombre del cualquier/radicalmente otro", que "entonces cualquier/radicalmente otro es cualquier/radicalmente otro" (78). Enseguida, tras decir que Dios se encuentra en todas partes donde haya algo que sea cualquier/radicalmente otro, Derrida dirá: "cada uno de nosotros, todo otro, cualquier/radicalmente otro es infinitamente otro en su singularidad absoluta, inaccesible, solitaria, trascendente, no manifiesta, no presente originariamente a mi ego" (78). Hay siempre una "relación sin relación" con el otro, el otro no aparece nunca originariamente sino como otro: "cualquier/radicalmente otro como cualquier 
radicalmente otro" (78). Es la referencia al alter ego husserliano, que puesta siempre en diálogo con Lévinas, señala que el otro "no se entrega nunca sino por analogía apresentativa y permaneciendo entonces radicalmente separado, inaccesible a la percepción originaria" (Derrida, Adiós, 73) ${ }^{24}$.

La relación entre Abraham y Dios es así, mediado por Husserl, y por Lévinas, la relación sin relación con "mi prójimo o los míos que me son tan inaccesibles, secretos y trascendentes como Yahvé" (Derrida, Dar la muerte 78). En un giro que recuerda $L a$ voz y el fenómeno y la relación entre la historia extraordinaria de Poe y la historia ordinaria del lenguaje $(C f$. Derrida, La voz 158-159), se dirá enseguida que el sacrificio de Isaac es la verdad traducida "en un relato extraordinario" y que "muestra la estructura misma de lo cotidiano". Que esta estructura se deje decir por un relato en el que se pide perdón por no querer decir, que este no querer decir anuncie la literatura, es lo que señalaremos enseguida. Ahora bien, esta estructura es la responsabilidad, enunciada en su paradoja, de cada instante para cualquiera. La unicidad absoluta de Yahvé, que encontramos en Kierkegaard, y que no tolera la analogía, es objeto de un desplazamiento con Husserl y Lévinas. Se nos ofrece una universalización y una diseminación de la excepción y de lo extraordinario que impone una complicación suplementaria a la generalidad ética. Lo que nos diría "la verdad paradójica de nuestra responsabilidad y de nuestra relación con el dar (la) muerte de cada instante". Pero también, nos explicaría "cuál es su propio estatuto, a saber, el poder aún ser legible para todos, en el momento mismo en que nos habla en secreto del secreto, de ilegibilidad, de indescifrabilidad absoluta" (Derrida, Dar la muerte 79), lo cual valdría para los judíos, los cristianos, los musulmanes, y para cualquier/ radicalmente otro. "No sabemos ya quien se llama Abraham, ni tampoco él puede ya decírnoslo".

$24 \quad$ Si se va hasta el fondo de este diálogo, lo que no podemos hacer aquí, se puede advertir tanto la necesidad de asumir, contra un infinitamente otro ajeno al fenómeno intencional, una "violencia trascendental" ligada "a la fenomenalidad misma y a la posibilidad del lenguaje" (Derrida, La escritura 168), como reconocer que si la intencionalidad fenomenológica "se abre desde el umbral de sí misma, en su estructura más general, como hospitalidad, acogida del rostro, ética de la hospitalidad, por consiguiente ética general" (Derrida, Adiós 71), si ya no se puede circunscribir, ni derivar, "si transita originariamente el todo de la experiencia intencional" (71), entonces "no tiene contrario" (71), es decir, "la hostilidad testimonia asimismo la hospitalidad" (72). 
Este no saber predispone a la literatura. Tanto como al secreto, que guarda Abraham. Porque no sabe en qué consiste el secreto, Abraham permanece en secreto, separado del secreto que guarda. Pide perdón por no querer decir, que es también no poder decir el secreto. "Perdón por no querer decir" es la frase que guarda el secreto porque permanece en el aire. Un secreto que "quizá no lo sea" es lo que anuncia la literatura. La literatura: "lo que, desde hace varios siglos, denominamos la literatura, lo que se denomina la literatura, en Europa, pero dentro de una tradición que no puede no ser heredera de la biblia, extrayendo de ella su sentido del perdón, pero pidiéndole a la vez perdón por traicionarla" (124).

En este contexto, en donde Derrida aborda la relación entre el no querer decir, la petición de perdón y la traición o el perjurio, es decir, la referencia a aquello mismo que se sacrifica, el cuchillo que se cierne sobre Isaac volverá a aparecer. Y con él, la problemática del tiempo. Todo, esta vez de la mano de la figura del meteorito. Y de lo meteórico.

Como el cuchillo de Abraham que da (la) muerte a Isaac incluso si es interrumpida por Dios, esta frase "queda suspendida en el aire incluso cuando toca" (125). Es que se mantiene en el aire, como una especie de meteorito, "antes o después de una caída, según el tiempo de esa caída posible" (125). O su contingencia. Se podría decir quizá del cuchillo en alto lo mismo que Derrida dice aquí de la frase meteórica: "pertenece al aire, al estar-en-el-aire". Pero si antes el cuchillo en alto era ya dar (la) muerte de hecho suspendida, ahora es el suspenso mismo de un secreto absoluto, que nunca deja de ser secreto, lo que se guarda compartiéndolo. Es el ejemplo de Isaac:

Se mantiene en suspenso, tal vez encima de una cabeza, por ejemplo la de Isaac en el momento en que Abraham levanta su cuchillo sobre él, cuando no sabe mejor que nosotros lo que va a ocurrir, por qué Dios le ha pedido en secreto lo que le ha pedido, y por qué va tal vez a dejarle hacer o a impedirle hacer lo que le ha pedido que hiciese sin darle ninguna razón: secreto absoluto, secreto que hay que guardar compartiéndolo en lo que respecta a una secreto que no se comparte (124).

Otro ejemplo, que según Derrida no es solo un ejemplo, es el de Kafka en su Carta al padre. Ficticia, literaria, secreta, esa carta al padre habría quedado entre el hijo y él mismo. Pero, observa enseguida que "esa carta secreta no se torna literatura, en la literalidad de su letra, sino a partir del momento en que se expone a convertirse en cosa pública y publicable, archivo que se ha 
de heredar, fenómeno asimismo de herencia -o testamento que Kafka no destruyó-" (134). Lo que se da a heredar no es más que una huella dejada y que permanece tan legible como ilegible. Es el rostro crispado de su padre que ve Isaac en el momento de levantar el cuchillo. Es el legado de Kafka en cuyo abandono es convertido en palabra testamentaria dentro de un corpus literario, vuelto literario por ese mismo abandono. Abandono abandonado a su deriva "por el secreto, por la destinerrancia del origen y del fin, de la destinación y del destinatario, del sentido y del referente de la referencia que sigue siendo referencia en su propia suspensión" (134-135).

\section{BIBLIOGRAFÍA}

Culler, Jonathan. On Deconstruction. Cornell University Press, 1982.

Derrida, Jacques. Canallas. Madrid: Trotta, 2003.

Espectros de Marx. Madrid: Trotta, 2002.

Le toucher. París: Galilée, 2000.

"La phénoménologie et la clôture de la metaphysique". Alter 8 (2000): 69-84.

Dar la muerte. Barcelona: Paidós, 1999.

Adiós a Emmanuel Lévinas. Madrit: Trotta, 1998.

Donner le temps. París: Galilée, 1991.

Le problème de la genèse dans la philosophie de Husserl. París: PUF, 1990.

Force de Loi. París: Galilée, 1994.

La escritura y la diferencia. Barcelona: Anthropos, 1989.

La voz y el fenómeno. Barcelona: Anthropos, 1985.

Prejugés. Devant la loi. París: Minuit, 1985.

Le Respect. Irvine: Seminario Inédito, 1980-1981.

Du droit à la littérature. Irvine: Seminario Inédito, 1978-1979.

La diseminación. Madrid: Fundamentos, 1975.

Littérature et verité: Le concept de mimesis, Irvine: Seminario Inédito, 1968-1969.

De la grammatologie. París: Minuit, 1967.

"Introduction" à l'Origine de la Géométrie de Husserl. París: PUF, 1962.

Derrida, Jacques y Derek Attridge. "Esa extraña institución llamada literatura. Una entrevista de Derek Attridge con Jacques Derrida", Boletín del Centro de Estudio de Teoría y crítica literaria $\mathrm{N}^{\circ}$ 18, 2017. www. Cetycli.org [Jacques Derrida y Derek Attridge, "Cette étrange institution qu'on appelle la littérature”. Derrida d'ici, Derrida de là. París: Galilée, 2009].

Derrida, Jacques y Elisabeth Roudinesco. Y mañana qué. México: FCE, 2005. 
Gasché, Rodolphe. Le Tain du Miroir. París: Galilée, 1995.

Husserl, Edmund. Ideas I. México: FCE, 1962.

Kamuf, Peggy. A Derrida Reader. Between the Blinds. Columbia: Columbia University Press, 1991.

Miller, Hillis. "Derrida and the literature". Ed. Tom Cohen. Jacques Derrida and the Humanities. A Critical Reader. Cambridge University Press, 2001. 58-80.

Trujillo, Iván. De la possibilité d'une fiction historique chez Derrida. París: L'harmattan, 2017. 